\title{
Management Strategies of Major Hepatobiliary Cysts - A Retrospective Study of 145 Consecutive Patients
}

\author{
M ALI $^{\mathrm{a}}$, MM RASHID $^{\mathrm{b}}, \mathrm{MM} \mathrm{HUSAIN}^{\mathrm{c}}, \mathrm{H}_{\mathrm{RABBI}}^{\mathrm{d}}$, AHMT AHMED $^{\mathrm{e}}, \mathrm{KM} \mathrm{AKHTER}^{\mathrm{f}}$, \\ H ALAM $^{\mathrm{g}}$, A FARUQ ${ }^{\mathrm{h}}$, T NARMIN ${ }^{\mathrm{i}}$, F YASMIN ${ }^{\mathrm{j}}$
}

\begin{abstract}
Summary:
Hepatobiliary cysts consist of a heterogeneous group of diseases that differ in cause, prevalence and manifestations. Some are found incidentally on imaging studies and tend to have a benign course. Symptomatic cysts and those become endanger to life need adequate treatment. We are reporting clinical and pathological features of 145 patients with different types of Hepatobiliary cysts along with their therapeutic approaches and outcomes. Study period was September 1997 to July 2006 (107 months). The most common was simple cyst followed by hydatid and choledochal cysts. Fifty-four (37.25\%) cysts were asymptomatic and diagnosed incidentally, 75 (51.72\%) had some form of symptoms; like abdominal pain, discomfort and swelling. Complications like obstructive jaundice; portal hypertension, vena caval obstruction, bronchobiliary fistula and peritonitis are noted in remaining 16 (11.03\%)
\end{abstract}

a. Prof. Mohammad Ali, FCPS FRCS Ed FACS, Professor \& Head, Dept. of Hepato-Biliary Pancreatic Surgery (HBPS), BIRDEM Hospital, Dhaka

b. Dr. Md Mamunur Rashid, FCPS, Assistant Professor, Dept. of Hepato-Biliary Pancreatic Surgery (HBPS), BIRDEM Hospital, Dhaka

c. Dr. Muhd. Mustaque Husain, FCPS, Assistant Professor, Dept. of Surgery, BIRDEM Hospital, Dhaka

d. Dr. Hashim Rabbi, MRCS Ed, Registrar, Dept. of HepatoBiliary Pancreatic Surgery (HBPS), BIRDEM Hospital, Dhaka

e. Dr. AHM Tanvir Ahmed, MBBS, Assistant Registrar, Dept. of Hepato-Biliary Pancreatic Surgery (HBPS), BIRDEM Hospital, Dhaka

f. Dr. Kazi Mahbuba Akhter, MBBS, Senior Medical Officer, Dept. of Hepato-Biliary Pancreatic Surgery (HBPS). BIRDEM Hospital, Dhaka

g. Dr. Hasina Alam, MBBS, Medical Officer, Dept. of HepatoBiliary Pancreatic Surgery (HBPS), BIRDEM Hospital, Dhaka

h. Dr. Amreen Faruq, MBBS, Senior Medical Officer, Dept. of Hepato-Biliary Pancreatic Surgery (I-IBPS), BIRDEM Hospital, Dhaka

i. Dr. Tamanna Narmeen, MBBS, Senior Medical Officer, Dept. of Hepato-Biliary Pancreatic Surgery (HBPS), BIRDEM Hospital, Dhaka

j. Dr. Farzana Yasmin, MBBS, Medical Officer, Dept. of HepatoBiliary Pancreatic Surgery (HBPS), BIRDFIM Hospital, Dhaka

Address of Correspondence: Prof. Mohammad Ali, FCPS FRCS Ed FACS, Professor \& Head, Department of Hepato-BiliaryPancreatic Surgery (HBPS), Room \# 911, BIRDEM Hospital, Shahbagh,Dhaka, Bangladesh. Phone:880-2-9661551 - 60 / 2464, Fax: 880-2-8613004. E-mail: hbbirdem@yahoo.com

Received: 3 December, 2007

Accepted: 27 November, 2008 symptomatic patients. They were treated by partial pericystectomy with omentoplasty (44.83\%), excision of the cyst with Roux-en-Y Hepaticojejunostomy or Cholangiojejunostomy (16.55\%), partial pericystectomy with closure of the biliary leakage and omentoplasty (13.8\%), closed total cystectomy (5.52\%), right or left typical or atypical hepatectomy (14.49\%), segmental deroofing and fenestration (4.8\%). There were no operative deaths or major postoperative complications. The recurrence was documented in 7 patients (4.83\%) in the follow up period. Three patients with hepatobiliary cystadenocarcinoma died during follow-up.

In summary, Clinico-pathological features, therapeutic approaches and outcome of 145 Hepatobiliary cysts after surgery has been discussed in the light of published literatures.

(J Bangladesh Coll Phys Surg 2009; 27: 13-21)

\section{Introduction:}

Hepatobiliary cysts are well known since ancient time. Brodie first described these cysts as hepatic cysts in $1846^{1}$. This "liver water" or cysts creates diagnostic and therapeutic dilemma in different situations. About $4 \%$ of the total populations have some form of liver cyst during their lifetime. Most of them are asymptomatic; do not require any surgical intervention. But those are symptomatic and become endanger to life require surgical treatment. Small simple cysts are asymptomatic but the larger one produces symptom. They destroy liver parenchyma; obstruct hepatic vein, portal vein, bile duct and inferior vena cava. Rupture of the cyst causes considerable morbidity and mortality. Management of these cysts is inevitable for treatment of the ailments and preventing further damage of the hepatic parenchyma or life threatening complications. Choledochal cysts are associated with pancreatobiliary maljunction (PBM) and have a high risk of malignancy ${ }^{2}$. Total excision of the cyst is therefore mandatory for curative intent ${ }^{3,4}$. Diagnosis of neoplastic cysts like hepatobiliary cyst adenoma and cystadenocarcinoma still remains in a dilemma. Proper diagnosis and adequate surgical intervention is mandatory ${ }^{5-9}$. 


\section{Materials and Methods:}

We have treated 145 patients with Hepatobiliary cysts at the BIRDEM and other Hospitals of Dhaka between September 1997 and July 2006 (107 months). There were 5 children \& 140 adults and their mean age was 48.8 (range $1.5-80$ ) years. The size of cysts was 4 to $35 \mathrm{~cm}$ (average: $19.5 \mathrm{~cm}$ ). The number of cysts was 1 to 4 in each patient. Data were extracted retrospectively from patient's hospital records for demographics, clinical presentations, types of surgical intervention, histological findings and outcomes.

A simple cyst was defined sonographically as a hypo echoic fluid-filled space occupying lesion with well demarcated wall. Hydatid cyst was diagnosed on the ultrasonography (US) and Computerized Tomography (CT) appearance of multilocular cystic lesion with daughter cysts, split wall, detached membrane, septations, and calcification of cyst wall. Indirect haemagglutination assay (IHA) was done for echinococcus infestations. Choledochal cyst was suspected by the US findings as cystic appearance of intrahepatic or extrahepatic biliary system. Endoscopic Retrograde Cholangio Pancreatography (ERCP), Magnetic resonance cholangiogram (MRC) and CT scan were done for evaluation of the patients with choledochal cysts.. Vertical reconstruction of CT scan is very helpful in evaluating hepato-biliary cysts.

Diagnosis of Hepatobiliary cystadenoma and cystadenocarcinoma were made by CT scan appearance of irregular thick wall, septations, calcification of septa and papillary projections. Nodular and irregular cyst margin with mucinous or hemorrhagic contents were the strong suspicion of neoplastic cysts.

Polycystic liver disease (PLD) was diagnosed by multiple cystic lesions in both lobes of liver, usually associated with cystic lesion in other organ commonly, as in kidneys. Histological confirmation and clinical correlation was made in all the cysts after surgery.

\section{Statistical analysis}

The chi-square test was used to assess significant between proportions. A value of $\mathrm{p}<0.05$ was considered statistically significant.

\section{Results:}

In the present series, of 145 Hepatobiliary cysts, 121 were hepatic cysts and 24 were biliary cyst (choledochal cyst). The numbers of non-parasitic cysts were $77(53.1 \%)$, of which simple cysts 70 (48.27\%), polycystic liver disease $5(3.45 \%)$ and caroli's disease $2(3.8 \%)$. There were 30 parasitic cysts and 14 neoplastic cysts (Table-I). Fifty-four $(37.25 \%)$ cysts were asymptomatic and diagnosed incidentally. They were submitted to operation for increasing size of the cyst, suspicion of malignancy or patients' desire to remove the cyst. Seventy-five patients $(51.72 \%)$ presented with some form of symptoms, 14 with abdominal pain, 45 with hepatomegaly, 16 with infections and other with nonspecific symptoms. Sixteen patients (11.03\%) presented with complications; 3 extra hepatic bile duct compression, 2 intrahepatic bile duct compression, 2 portal vein compression (combined portal vein $\&$ bile duct in one), and 1 vena cava compression, 2 rupture of the cyst, 3 disseminated hydatid cyst and 1 bronchobiliary fistula (Table-II). Thirty six (24.82\%) patients had recurrent cyst, they underwent previous surgical intervention in other institutions. Among the recurrent cysts, 12 were simple cysts, 15 hydatid cysts, 3 cystadenoma, 2 cystadenocarcinoma and 4 choledochal cysts. Eleven simple cysts recurred after previous ultrasound guided percutaneous drainage and one following Roux-en-Y cystojejunostomy due to blockage of cysto-jejunal anastomotic loop by the cirrhotic changes in adjacent portion of the liver.

\section{Table-I}

Types of hepatobiliary cysts $(n=145)$

\begin{tabular}{lcc} 
Types of cysts & $\mathrm{n}$ & $\%$ \\
\hline Hepatic cyst & 121 & 83.45 \\
a Nonparasitic cyst & 77 & 53.1 \\
- Simple cyst & 70 & \\
- Polycystic disease & 5 & \\
- Caroli's disease & 2 & \\
b. Parasitic cyst (Hydatid) & 30 & 20.69 \\
c. Neoplastic cyst & 14 & 9.6 \\
- Cystadenoma & 10 & \\
- Cystadencarcinoma & 4 & \\
Biliary cyst (Choledochal) & 24 & 16.55 \\
\hline Total & 145 & 100 \\
\hline
\end{tabular}




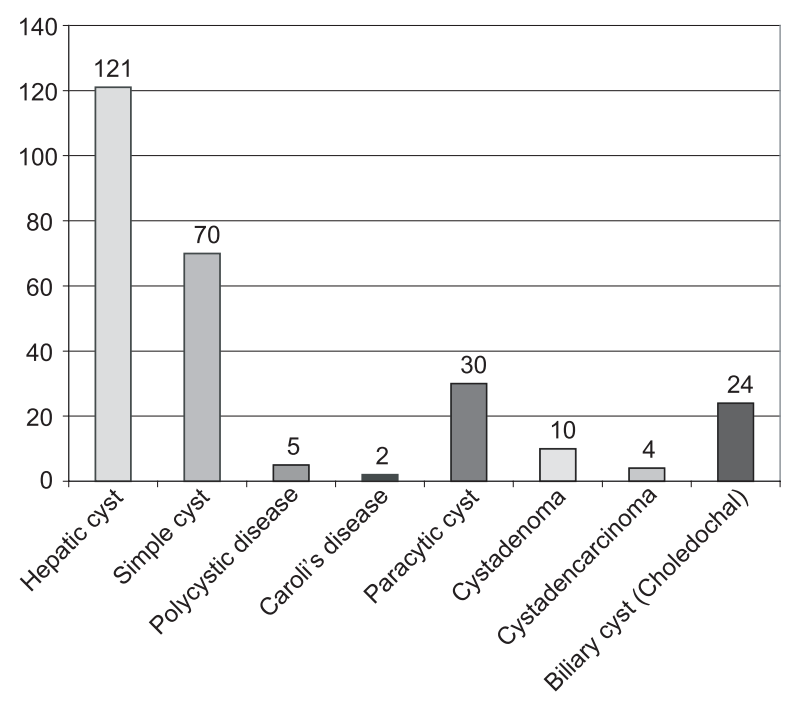

Fig. 1: Types of hepatobiliary cysts $(n=145)$

Table-II

\section{Presentation of patients with Hepatic cysts $(n=145)$}

\section{Parameters}

Asymptomatic

Symptomatic

- Abdominal pain

- Hepatomegaly

- Infections \& vague symptoms

Complications

- Extrahepatic biliary tract compression 3

- Intrahepatic biliary tract compression 2

- Portal compression 2

- Vena caval compression 1

- Rupture of the cyst 2

- Dissemminated hydatid cyst 3

- Peritonitis

- Bronchobiliary fistula

1

There was diagnostic dilemma in 12 patients $(8.27 \%)$. The extrahepatic cystic lesions like suprarenal cyst, retroperitoneal cysts, and pancreatic cyst were wrongly labeled as liver cysts by imaging. Laparotomy revealed no hepatic cystic lesions in those patients. Intrahepatic lesions like hemangioma, liver abscess, cystic degeneration of liver tumours were noted in 4 patients. All the extrahepatic cystic lesions and noncystic intrahepatic lesions were treated accordingly and were excluded from the study.

Cystectomy with omentoplasty done in 93 (64.13\%) cases of hepatic cysts, 21 cases were treated by hepatectomy and 7 by segmental de-roofing and fenestration. Twenty-four choledochal cysts (16.55\%) were treated by excision of the cyst with Roux-en-Y hepaticojejunostomy (Table-III).

\section{Table-III}

Surgical treatment of hepatobiliary cysts $(n=145)$

\begin{tabular}{lcc} 
Types of surgery & $\mathrm{n}$ & $(\%)$ \\
\hline Cystectomy with omentoplasty & 93 & $(64.13)$ \\
Hepatectomy & 21 & $(14.48)$ \\
Segmental deroofing / fenestration & 07 & $(4.83)$ \\
Total cystectomy with & 24 & $(16.55)$ \\
roux-en-Y hepatico-/ & & \\
cholangio-jejunostmy & & \\
\hline Total & 145 & $(100 \%)$ \\
\hline
\end{tabular}

Analysis of clinico-pathological data of different hepatic cysts revealed that the incidence of nonparasitic cyst was significantly higher than parasitic and neoplastic cysts $(\mathrm{p}<0.01)$. The ages of patients with neoplastic cyst were significantly higher than the age of patients with non-parasitic and parasitic cysts $(\mathrm{p}<0.01)$. Neoplastic cysts were presented with symptoms more frequently $(p<0.01)$ than parasitic and nonparasitic cysts. Most of the non-parasitic cysts and all parasitic cysts were treated by cystectomy where as the all neoplatic cysts needed hepatectomy (Table-IV).

There were no operative deaths or major postoperative complications. Follow-up was given in 90 patients $(62.06 \%)$. Wound infections were found in 10 patients. The recurrence was documented in 7 patients $(4.83 \%)$, 6 with hydatid cyst and one with cystadenoma. Three patients with hepatobiliary cystadenocarcinoma died, one with cardiac disease, and the other with metastasis during follow-up (Table -V). 


\section{Table-IV}

Comparison of clinicopathological data among different types of hepatic cysts $(n=121)$

\begin{tabular}{|c|c|c|c|c|c|c|}
\hline \multirow[t]{2}{*}{ Parameters } & \multicolumn{2}{|c|}{ Non-parasitic cyst } & \multicolumn{2}{|c|}{ Parasitic cyst } & \multicolumn{2}{|c|}{ Neoplastic cyst } \\
\hline & $\mathrm{n}$ & $(\%)$ & $\mathrm{n}$ & $(\%)$ & $\mathrm{n}$ & $(\%)$ \\
\hline Incidence of cyst & 77 & $(63.63)^{*}$ & 30 & $(24.79)$ & 14 & $(11.57)$ \\
\hline Mean age (range) years & 46.2 & $(34-64)$ & 34.6 & $(1.5-55)$ & 71.3 & $(68-80)^{* *}$ \\
\hline Symptoms & 21 & $(27.27)$ & 08 & $(26.66)$ & 10 & $(71.42)^{* *}$ \\
\hline \multicolumn{7}{|l|}{ Procedures } \\
\hline - Cystectomy & 70 & $(90.90)$ & 30 & (100) & 0 & \\
\hline - Hepatectomy & 07 & $(9.09)$ & 0 & & 14 & $(100)^{* *}$ \\
\hline
\end{tabular}

$* \mathrm{p}<0.01$, non-parasitic vs parasitic \& neoplastic

** $\mathrm{p}<0.01$, neoplastic vs non-parasitic\& parasitic

Table-V

Outcome of patients with hepatic cysts $(n=145)$

Parameters

Morbidity

- Wound infections

- Incisional hernia

- Persistent discharge from wound

- Subhepatic abscess

Mortality

- Operative

- Hospital

Recurrence rate*

Patient follow up

Follow up period (months)

Death during follow up**

$\begin{array}{cc}\mathrm{n} & \% \\ 29 & 20 \\ 10 & 6.9 \\ 4 & 2.76 \\ 8 & 5.52 \\ 3 & 2.76\end{array}$

* Cystadenoma $(\mathrm{n}=01)$, hydatid cyst $(\mathrm{n}=06)$

** Hepatic cystadenocarcinoma with heart disease

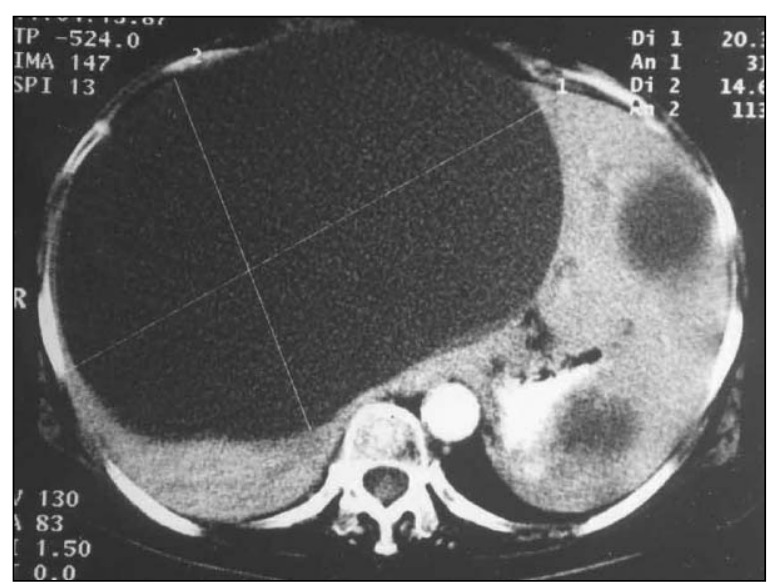

(a) CT sca

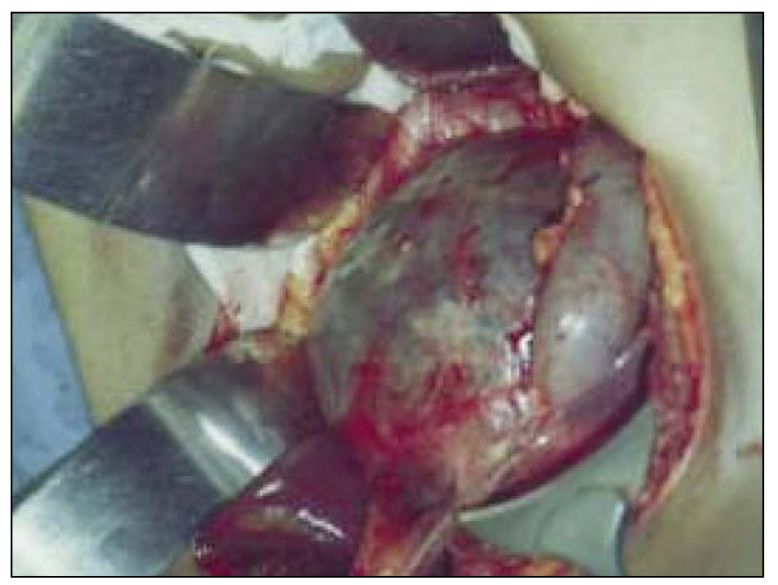

(b) Peroperative view

Fig.2: Simple hepatic cyst (right lobe) 


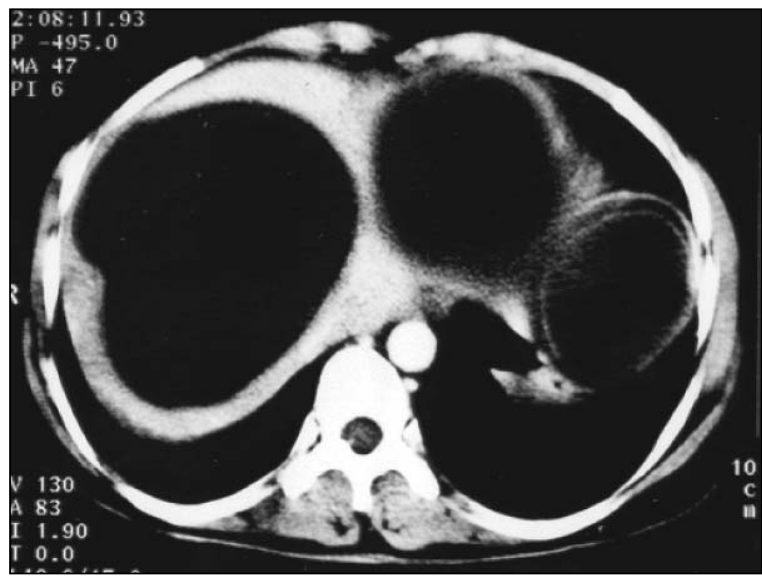

a. Multiple simple cysts

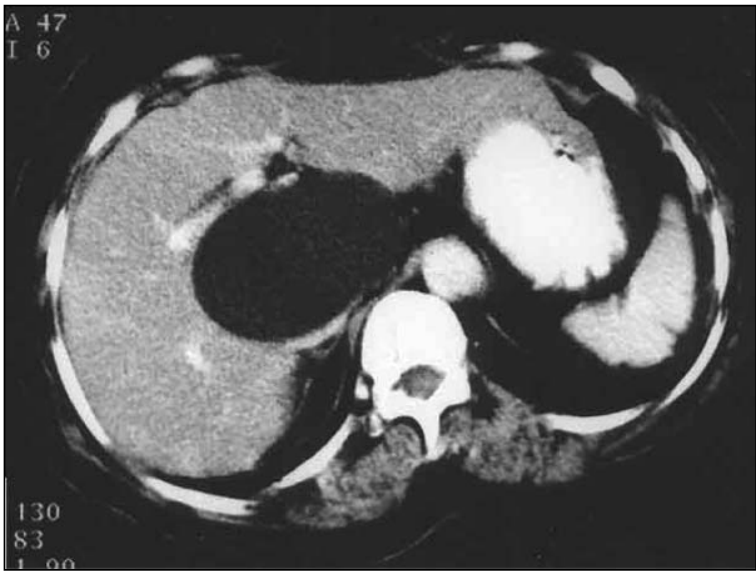

c. Cyst of the caudate lobe of liver.

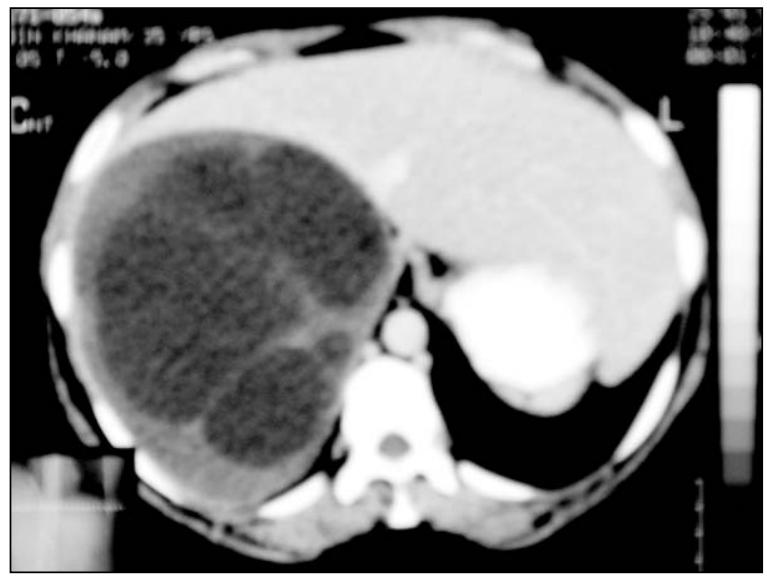

e. Cystadenoma

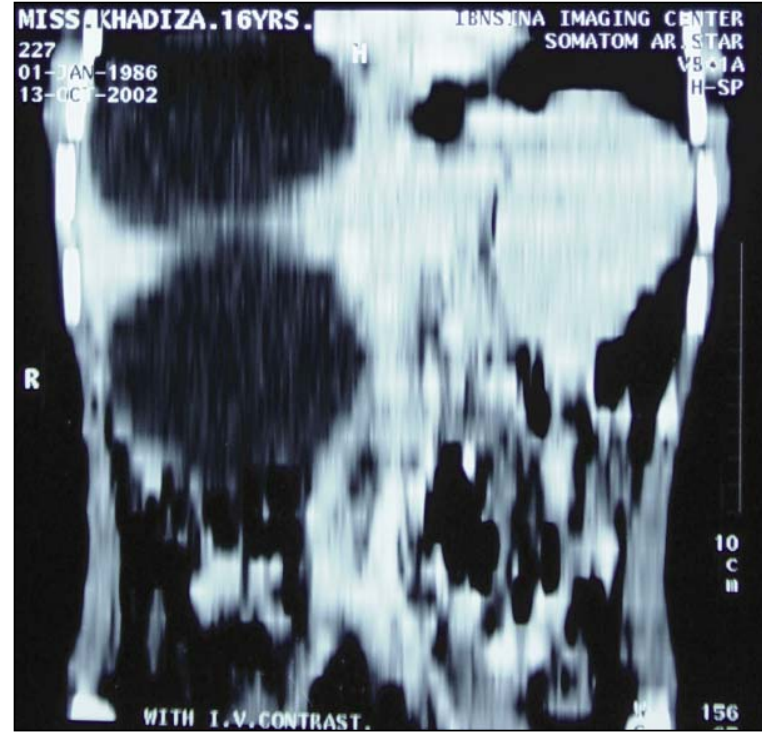

b. Hour glass configuration of simple cyst

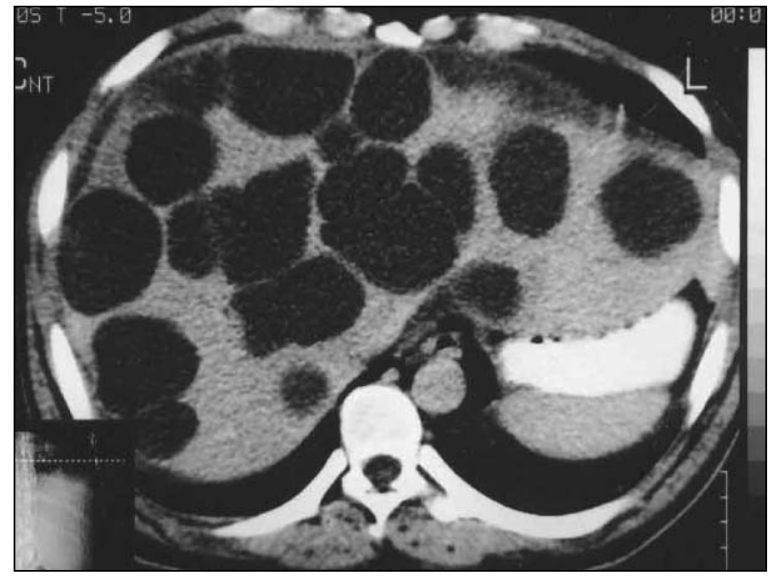

d. Polycystic liver disease

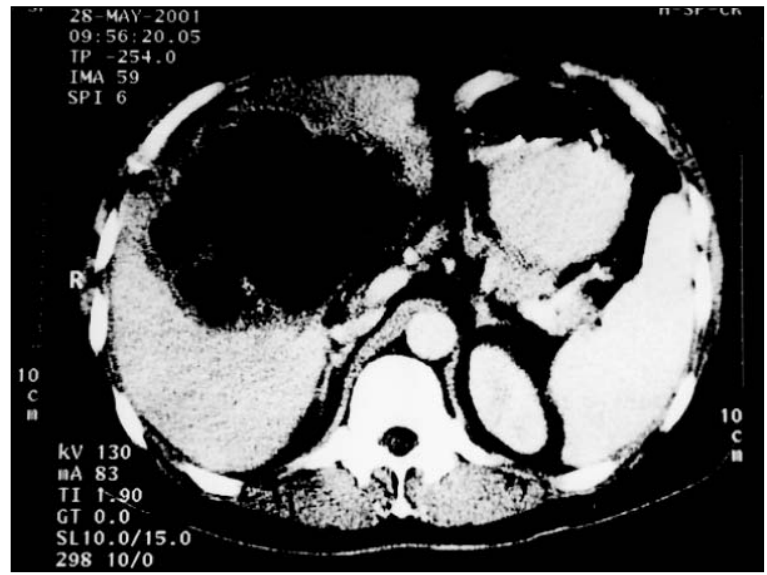

f. Cystadenocarcinoma

Fig.3: Different types of hepatic cysts (white arrow). 


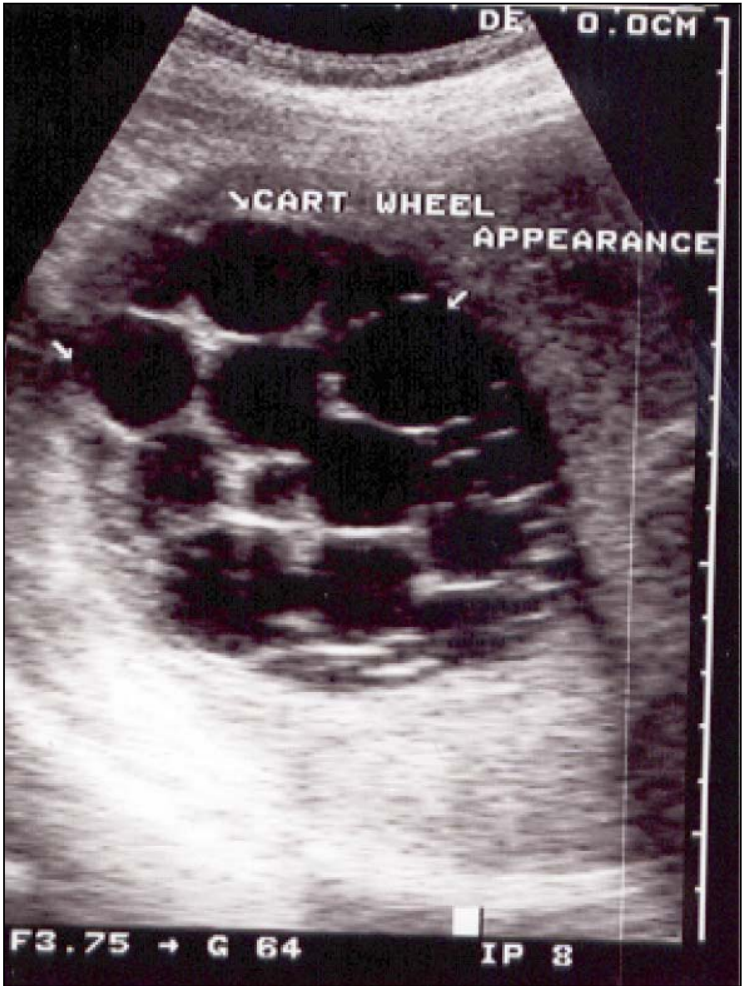

Fig.4: Hydatid Cyst of Liver. a. 'Honey comb' appearance at USG

\section{Discussion:}

The present series included almost all types of common cysts of the hepatobiliary system. Most of the cysts were larger in size and complicated due to their mechanical and infective elements. The higher proportions of these symptomatic cases were due to the referral to specialized Hepatobiliary Pancreatic surgery services. All the patients evaluated initially by ultrasonography. CT scan done for $90 \%$ of the patients to understand the nature and extent of the cyst. ${ }^{10,11,12}$ Indirect hemagglutination (IHA) test was performed in $80 \%$ of patients with hydatid cysts. However, hydatid cyst was confirmed in 8 patients with negative IHA test. This finding is consistent with the report of Kagon et al ${ }^{13}$. Hydatid cyst filled with an amorphous mass may simulates the neoplastic lesions of the liver in imaging, which creates diagnostic problem ${ }^{14}$.

We strictly followed the principle of operative management of liver hydatid cyst $^{15}$. Adequate exposure, safe external decompression of the cyst,

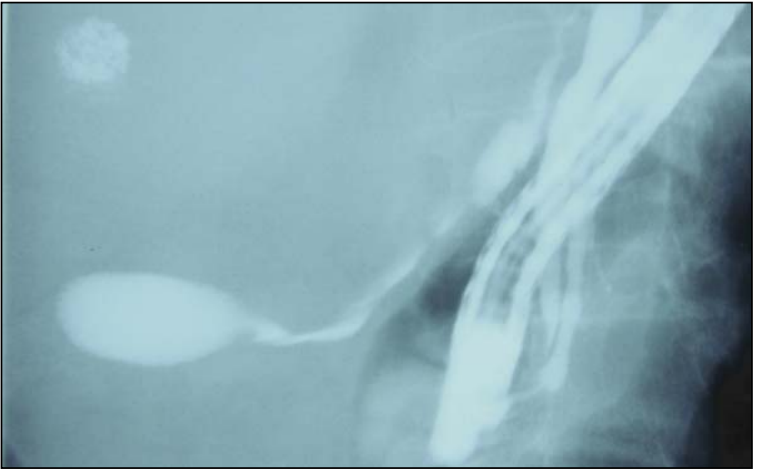

a. Compressing the biliary tract.

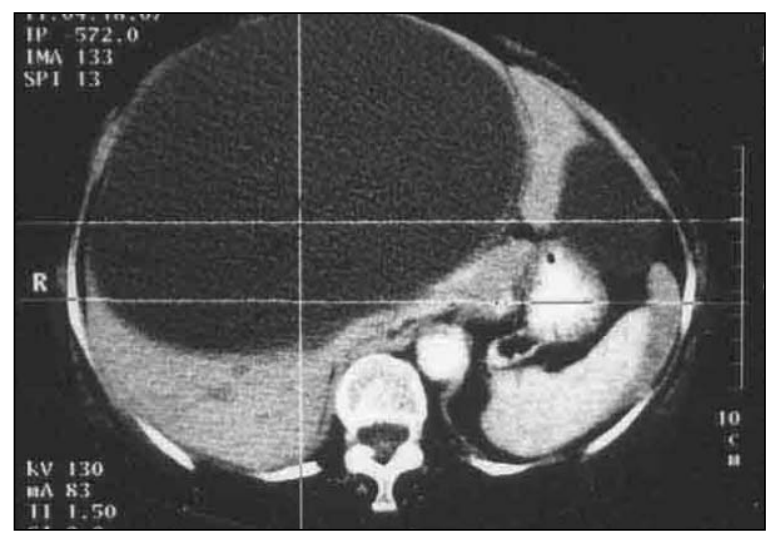

b. Compressing the vena cava

Fig.5: Complications of simple hepatic cyst

and prevention of peroperative spillage of cyst contents are mandatory. Hypertonic Sodium Chloride solution $(3 \% \mathrm{NaCl})$ was used as scolicidal agent. Cystobiliary communications were closed with suture. Roux-en-Y cholangiojejunostomy was performed in 2 patients to preserve the functioning hepatic parenchyma. Minor postoperative bile leak was noted in 8 patients, which were closed spontaneously in about 3 weeks time. All the hydatid cyst patients received albendazole $(400 \mathrm{mg}$ b.i.d. or $10 \mathrm{mg} / \mathrm{kg} /$ day) for 2 weeks preoperatively and 4 weeks postoperatively ${ }^{16}$. Five patients having multiple hydatid cysts with severe fibrosis were treated by atypical resection of hepatic lobe. Patients with disseminated hydatid needed wide excision of the omentum and other structures including resection and anastomosis of small and large bowel. ${ }^{17,18}$ Hydatid cyst with Broncho biliary fistula needed hepatic resection and thoracotomy for the closure of the fistula ${ }^{19}$. In one patient hydatid cyst ruptured into the biliary tree and developed obstructive jaundice. 
He was treated by choledochotomy, removal of hydatid materials \& partial excision of the cyst. Omentoplasty was done in all patients with partial cystectomy. Fifteen patients with recurrent hydatid cyst who had previous surgery in other centers were treated by partial excision or atypical liver resection. Recently, a new technique called Puncture Aspiration Installation of Scolicidal and Reaspiration (PAIR) is being practiced for percutaneous drainage of hepatic hydatid cyst. ${ }^{20-25}$ This procedure sometime produces complications like bleeding, peritonitis, anaphylaxis, allergic reactions and biliary complications ${ }^{26}$. Inadvertent installation of sclerosing agent into a cyst with biliary communication can cause sclerosing cholangitis. ${ }^{27,28}$ PAIR procedure could not be applied in our patients because of advanced state of the cyst and possibility of such complications.

Symptomatic simple cyst is usually treated by various surgical procedures. ${ }^{29-32}$ Large cyst in the central region causes compression of the portal vein and bile duct causing portal hypertension and obstructive jaundice noticed in one patient. ${ }^{33}$ Another patient presented with leg oedema because of the compression of inferior vena cava by a large simple cyst in most part of right lobe. A 19-months old girl had a large cyst in her liver with three cavities in it. One cavity contained clear fluid; second one was bile stained and the last one with purulent materials. These complicated cysts treated successfully by partial pericystectomy with omentoplasty ${ }^{34-36}$.

Most of the patients of choledochal cyst were associated with anomalous pancreatobiliary junction ${ }^{37}$. These cysts have high malignant potential. ${ }^{38}$ Complete excision of the cyst from the pancreatobiliary junction up to the level of proximal duct with healthy biliary mucosa is the standard method. This procedure was performed in 18 patients. Six patients of choledochal cyst had severe fibrous adhesion with portal vein and hepatic artery. Mucosal resection was performed up to the proximal healthy mucosa in those 6 patients. ${ }^{34,38-41}$ Biliary reconstruction was performed by Roux-en-Y hepaticojejunostomy in all patients. Histopathology examination of all the choledochal cysts was done to exclude malignancy.

Sequential fenestration and excision is commonly performed in patients with polycystic liver disease. It relieves compression and the intervening hepatic parenchyma. ${ }^{42}$ Five patients of the present series had polycystic disease and they were treated by sequential fenestration and excision of the cysts.

Caroli's diseases with multiple intrahepatic cystic lesions were noted in two patients. Hepatic resection with or without cholangiojejunostomy is the effective treatment for Caroli's disease when the cysts are located in an anatomical lobe. ${ }^{43-46}$ In both of our patients with Caroli's disease, cysts were confined in the left lobe. Left hepatectomy was performed in one patient, and left hepatectomy with Roux-en-Y Cholangiojejunostomy in another.

The preferred treatment of cystadenoma is complete resection whenever possible, because of potential malignant transformation of the cyst. Partial excision of cyst adenoma and cystadenocarcinoma is invariably associated with recurrence and with poor prognosis ${ }^{47}$. Of the 14-neoplastic cysts, all were treated by typical hepatectomy. During follow up recurrence of cystadenoma in one case was recorded.

Recurrent liver cyst following previous ultrasonic guided percutaneous drainage was noted in 36 patients of the present series. They were successfully treated by excision of cyst. These findings discourage the percutaneous drainage procedure in treating liver cyst ${ }^{29}$.

Recently it has been reported that laparoscopic management of liver cyst could be done safely 48,49 . But the scope of laparoscopic approach is limited in large \& complicated cysts.

There was no immediate or 30-day postoperative mortality; however, morbidity occurred in 29 patients $(20 \%)$. Maximum follow up was 112 months (up to December 2006). Ninety patients $(62.07 \%)$ were available for follow-up. Seven patients had recurrence of cysts and 3 patients died during followup - One due to recurrence of the cystadenocarcinoma and the other two of co morbid cardiac diseases.

This present study of 145 patients of hepatobiliary cysts includes most of the kinds of cysts in the liver and the biliary tree reported in the literatures. 


\section{Conclusion:}

The cystic lesions in the liver and biliary system is a common disorder. It may closely simulate the features of other hepatic or extra hepatic lesions. Histopathological examinations for all cystic lesions are mandatory, otherwise premalignant and malignant lesions may be missed. The symptomatic hepatic cysts demand a wide spectrum of hepatobiliary surgical strategies. It ranges from simple procedures to liver resections, biliary reconstructions and even liver transplantations for the end stage liver disease due to big cysts in certain circumstances. Adequate surgical intervention can offer cure in most of the patients.

\section{Reference:}

1. Brodie BC. Lectures illustrative of various subjects in pathology and surgery: Lecture V. Longman, London, 1846.

2. Komi M, Takehara H, Kunitomo K. Choledochal cyst: anomalous arrangement of pancreaticobiliary ductal system and biliary malignancy. J Gastroenterolgy \& Hepatology 1989; 4: 63-74

3. Lilly JR. The surgical treatment of choledochal cyst. Surgery, Gynecology \& Obstetrics. 1979; 49: 36-42.

4. Komi N, Tamura T, Miyoshi Y, Kunitomo K, Udaka H, Takehara H. Nationwide survey of cases of choledochal cysts: analysis of coexistent anomalies, complications and surgical treatment in 645 cases: Surgical Gastroenterology. 1984; 3: 69-73.

5. Choi BI, Lim JH, Han MC, et al. Biliary cystadenoma and cystadenocarcinoma: CT and sonographic findings. Radiology. 1989; 171: 57-61.

6. Lewis WD, Jenkins RL, Rossi RL et al. Surgical treatment of biliary cystadenoma. A report of 15 cases. Archives of Surg. 1988; 123: 563-568.

7. L.arsen KA. Benign lesions affecting the bile ducts in the post mortem cholengiogram. Acta pathologica, microbiologica et immunologica Scandinavica, 1961; $51: 47-62$.

8. Taylor BR, Langer B. Current surgical management of hepatic cyst disease. Adv Surg 1997;31:127-148

9. Henson SW Jr, Gray HK, Dockerty MB. Benign tumors of the liver. Solitary cysts. Surg Gynecol Obstet. 1956; 103: 607-611

10. Nisenbaum HL, Rowling SE. Ultrasound of focal hepatic lesions. Semin Roentgenol. 1995; 30: 324-346

11. Spiegel RM, King DL, Green WM. Ultrasonography of primary cysts of the liver. AJR Am J Roentgenol. 1978; 131: $235-338$

12. Contreras MC, Letonja T, Salinas P, Munaz ME, Sandoval L. Diagnostic titre for hydatidosis by using indirect heamagglutination test. Boletin Chieleano de Parasitologia. 1978; 33: 53-56

13. Kagan IG. A review of serological tests for the diagnosis of hydatid disease. Bulletin of the World Health Organization 1968; 39: 25-37

14. Niron EA, Ozer H. Ultrasound appearance of liver hydatid disease. British J Radiol. 1981; 54: 335-338

15. Avgerinos ED, Pavlakis E, Stathoulopoulos A, Manoukas E, Skappas G, Tsatsoulis P. Clinical presentation andsurgical management of liver hydatidosis: Our 20 year experience. HBP, 2006; 8: 189 - 193.

16. Morris DL Clarkson MJ, Stallbaumer MF, Pritchard J, Jones RS, Chinnery JB. Albendazole treatment of pulmonary hydatid cysts in naturally infected sheep:a study with relevance to the treatment of hydatid cysts in man. Thorax. 1985; 40:453-458

17. Behrns KE, Van Heerden JA. Surgical management of hepatic hydatid disease. Mayo Clinic Proceedings. 1991; 66: $1193-1197$

18. Langer JC, Rose DB, Keystone JS, Taylor BR, Langer B. Diagnosis and management hydatid disease of the liver. A 15-year North American experience. Ann Surg. 1984; 199: $\quad 412-417$

19. Reventos J, Nogueras FM, Rius X, Lorenzo T. Hydatid disease of the liver with thoracic involvement. Surg. Gnaecol \& Obs. 1976; 149: 570-574

20. Filice C, Pirola F, Brunnetti E, et al A new therapeutic approach for hydatid liver cysts : aspiration and alcohol injection under sonographic guidance. Gastroenerology 1990; 98: $\quad 1366-8$

21. Khuroo MS, Zargar SA, Mahajan R. Ecchinococcus granulosus cysts in the liver : management with percutaneous drainage Radiology 1991; 180: 141-5.

22. Khuroo MS, Dar MY, Yatto GN, et al. Percutaeneous drainage versus albendazole therapy in hepatic hydatidosis: a prospective randomized study. gastroenterology 1993; 104: $1452-9$

23. Gargouri M, Ben amor N, Ben Chehida F, et al. Percataeneous treatment of hydatid cysts (Ecchinococcus granulosis). Cardiovasc Intervent Radiolo1990; 13: 169-73

24. Akhan O, Ozman MN, Dincer A, sayek IS, GoemenA. Liver hydatid disease longb term results of percutaneous treatment. Radiology 1996; 198: 259-64

25. Brunnetti E, Filice C. Percutaneous aspiration in the treatment hydatid Liver cysts. Gut 1996; 38: 936

26. WHO Informal working group on Ecchinococcus. Guidelines for treatment of cystic and alveolar Echinococcosis in humans. Bull WHO 1996; 74:231- 42.

27. Castellano G, Moreno- Sanchez D, Gutierrez J, MorenoGonzalez E, Colina F, Solis- Herruzo JA, Caustic Sclerosing Cholangitis: report of four cases and a cumulative review of the literature. Hepatogastroenterology 1994; 41:458-70. 
28. Tsimoyiannis EC, Grantzis E, Muotesidou K, Lekkas ET, Secondary Sclerosing Cholangitis; after injection of formaldehyde into hytadid cyst in the liver. Eur J Surg 1995;161:299-300.

29. Saini S, Mueller PR, Ferrucci JT Jr, Simeone JF, et al. Percutaneous aspiration of hepatic cysts does not provide definite therapy. Am J Roentgenology. 1983; 141 : 559560

30. Goldstein H N , Carlyle D R, Nelson RS. Treatment of symptomatic hepatic cysts by percutaneous installation of pantopaque. Am J Roentgenology. 1976; 127: 850-853

31. Bean WJ, Rodan BA. Hepatic cysts: treatment with alcohol . Am J Roentgenology 1985; 144: 237-241.

32. Moreaux J,Bloch P. Les kystes biliaires solitaires du foie. Archives Franchaises des Maladis de1' Appareil Digestif 1971; 60: 203-224.

33. M Ali, H Rabbi, BC Das, NA Imam, S Roy, JA Chowdhury, M Rahman. Simple liver cyst with portal hypertension \& obstructive jaundice - Report of a case: Journal of Bangladesh College of Physicians and Surgeons. 2002: vol 20, no 2 : 98-101.

34. Arie Regev., K Rajender Reddy, Mariana Berho et al. Large cystic lesions of the liver in Adults: A 15-year experience in a tertiary center. J Am, Coll. Surg. 2001, 193 (1) : 36-45.

35. Soud S C, Watson A. Solitary cyst of the liver presenting as an abdominal emergency. Postgraduate Medical Journal. 1974; 50; 48-50.

36. Frisell J, Rodgmark S, Arvidsson H, Lundh G. Compression of the inferior caval vein. A rare complication of a large nonparasitic liver cyst. Acta Medica Scandinavica 1979; 205; 541-542.

37. Todani T, Watanabe Y, Fujii T, Uemura S. Anomalous arrangement of the pancreatobiliary ductal system in patients with a choledochal cyst. American Journal of Surgery. 1984; 147:672-676.

38. Yoshida H, Itali Y, Minami M, Kokubo T, Ohtomo K, Koroda A. Biliary malignancies occurring in choledochal cysts. Radiology. 1989; 173; 389- 392.
39. Todani T, Tabuchi K, Watanabe Y, Kobayashi T. Carcinoma rising in the wall of congenital bile duct cysts. Cancer. 1979; 44: 1134-1141.

40. Todani T, Watanabe Y, Fujii T, Toki A, Uemura S, Koike Y. Congenital Choledochal cyst with intrahepatic involvement. Achieves of Surgery. 1984; 119: 1038-1043.

41. Todani T, Watanabe Y, Toki A, Urushihara N. Carcinoma related to the choleodchal cysts with internal drainage operations. Surgery, Gynecology and Obstetrics. 1987; 164: 61-64.

42. Howard RJ, Hanson RF, Delany JP. Jaundice associated with polycystic liver disease. Relief by surgical decompression of the cyst. Archives Surgery. 1976; 111: 816-817

43. Mercadeir M, Chigot J P, Clot J P, Langlois P, lansiaux P, 1984 Caorli's disease . World Journal of Surgery 1984; 8: 22-29.

44. Ramond M-JHuguet C, Danan G, Rueff B, Benhamou J-P. Partial Hepatectomy in the treatment of Caroli's disease. Report of a case and review of the literature. Digestive Diseases and Sciences. 1984; 29:367-370.

45. Witlin L T, Gadacz T R, Zuidema G D, Kridelbaugh W W 1982. Transhepatic decompression of biliary tree in Caroli's disease. Sugery. 1982; 91: 205-209.

46. Ludwig J, Wiesner R H, LaRusso N F. Focal dilatation of intrahepatic bile ducts (Caroli's disease), cholangiocarcinoma, and sclerosis of intrahepatic bile ducts. Journal of Clinical Gastroenterology. 1982; 4:53-57.

47. Ishak KGWillisGW, Cummins SD, Buflock AA. Biliary cystadenoma and cystadenocarcinoma. Report of 14 cases and review of the literature. Cancer. 1977; 39: 322- 338 .

48. Diez J, Decoud J, Gutierrez L, Suhl A, Merello J. Laparoscopic treatment of symptomatic cysts of the liver. Br. J. Surg. 1998; 85: 25-27.

49. Marvik R, Myrvold HE, Johnson G, Roysland P. Laparoscopic ultrasonography and treatment of hepatic cysts. Surg Endosc. 1993; 3: 172-174. 